\title{
Analysis of vessel traffic and safety assessment of the Soya Strait
}

\author{
N. Sawano ${ }^{1}$, S. Hamada ${ }^{2} \&$ T. Arola ${ }^{3}$ \\ ${ }^{1}$ Inaoki Educational Institute \& Seiryo Women's Junior College, Japan \\ ${ }^{2}$ Geological Survey of Hokkaido, Department of Marine Geosciences, \\ Japan \\ ${ }^{3}$ Finnish Transport Agency, Maritime Department, Finland
}

\begin{abstract}
In order to acquire the true figure of vessels going through the Soya (La Perouse) Strait, an AIS (Automatic Identification System) receiving station was set up in November 2008 and data has been successfully stored. Both static and dynamic analyses were conducted. First, the Strait was divided into eight sections and directions and the numbers of vessels crossing each section were counted. Second, the area was divided into $1 \mathrm{~km}$ square grids, then each grid was examined as to whether two or more ships were in the same grid at the same time. As a result from the first analysis, vessels are crossing both bounds of west to east and east to west in each section. Large vessels with hazardous materials are likely to be congested in the northern part of the strait to keep away from the Reef Nijo and save petroleum, and dangerous crossings have actually occurred periodically. Lane separation or other traffic regularity needs to be established through international cooperation.
\end{abstract}

Keywords: automatic identification system (AIS), risk assessment, Soya (La Perouse) Strait, Sakhalin oil and natural gas developing projects.

\section{Introduction}

The Sea of Okhotsk is part of the western Pacific Ocean surrounded by Kamchatka Peninsula, Kuril Islands, the island of Hokkaido and the island of Sakhalin. In the Sea of Okhotsk off the island of Sakhalin, one of the largest oil and natural gas developing projects has been underway in earnest from the late 1990s. It is known that there are nine developing projects around Sakhlin Island 


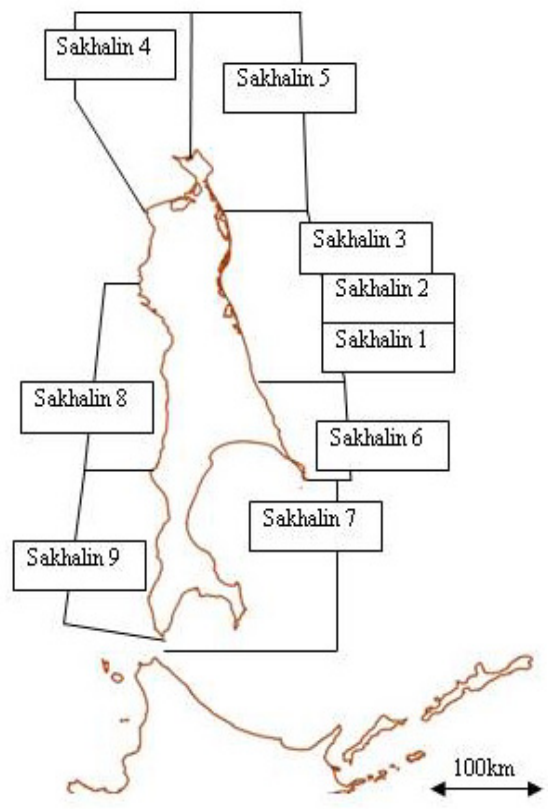

Figure 1: $\quad$ Location of Sakhalin oil developing projects.

and each project is called 'Sakhalin 1 to 9' according to the mining blocks (see Figure 1).

Among the nine projects, Sakhalin 1 and 2 have already started their production: Sakhalin 1 has reached $250 \mathrm{kbbl} \mathrm{day}^{-1}$ of maxium oil production as of Feburary 2007, meanwhile, Sakhalin 2 started LNG production in Feburary 2009. The total reserve of oil in Sakhalin 1 to 6 is estimated as being from 10.4 to 17.6 billion bbl. Three blocks after Sakhalin 6 have not been awarded yet and Sakhalin 7 to 9 are waiting for development $[1,2]$.

It should be noted that natural conditions of this area are more inhospitable than many other places for oil companies because of the unique combination of ice-covered waters, heavy weather conditions in winter as well as a constant threat of earthquakes.

'Inhospitality' seems to be reflected in the selection of construction methods. Chayvo, one of the drilling fields of Sakhalin 1, introduced ERD (Extended Reach Drilling), 8 to $11 \mathrm{~km}$ of horizontal drilling. "The hawk and the eagle", a newsletter of the Sakhalin 1 project reported that ERD enables oil production drilling all year-round in temperatures down to minus 40 degrees $\mathrm{C}$, in a coastal location where blinding winter snows tend to blow sideways at gale force. The rigs have to stand up to strong earthquakes such as the deadly 1995 Neftegorisk quake with the magnitude of 7.6 that struck some $80 \mathrm{~km}$ north of Chayvo [3].

In addition to the inhospitable natural conditions, this area is known as one of the most affluent fishing grounds in the world. The Sea of Okhotsk off the coast of Sakhalin provides over $60 \%$ of the Russian total annual catch. The fishing 
industry dominates the island's economy, employing over 50,000 of the island's 700,000 residents. In the shelf waters alone there are 70 different species of fish; in the Sea of Okhotsk, more than 300 [5]. This "fisheries condition" is also true for Japan. The total fish catch along the coastline of the Sea of Okhotsk, from Wakkanai to Shiretoko, is more than 4 times as much as that for the whole coastline of the Sea of Japan. The annual total sum is close to 300 billion JPY and this only represents the economic benefit of fish production. The direct income from the fishery also sustains numerous seafood fabricating companies and thus the total income that also includes the companion industries should be twice or more than that of the fishery itself [6].

\section{AIS (automatic identification system)}

\subsection{Installation of the AIS}

Soya Fishery Union (SFU) in Hokkaidō has been very concerned about the oil and natural gas developing projects conduced in the nearby waters of Japan. Before the developing projects began, SFU installed their own radar system to monitor their fishing grounds and prevent illegal fishing as well as resource control. To increase monitoring ability for shipborne risk, the authors' research team obtained permission to install an AIS station at Soya Misaki Branch of SFU. Figure 2 shows the location of the AIS station and coverage; Figure 3 shows the equipment such as the AIS antenna, T-300 AIS receiver and PC monitor.

The AIS has been developed for the purpose of supporting the safety and efficiency of vessel navigation. The system automatically and periodically exchanges navigational data, e.g. a ship's identification and her position on VHF frequencies between vessels as well as vessels to the coast. Because of the amendment of the SOLAS Convention, all passenger vessels engaging for

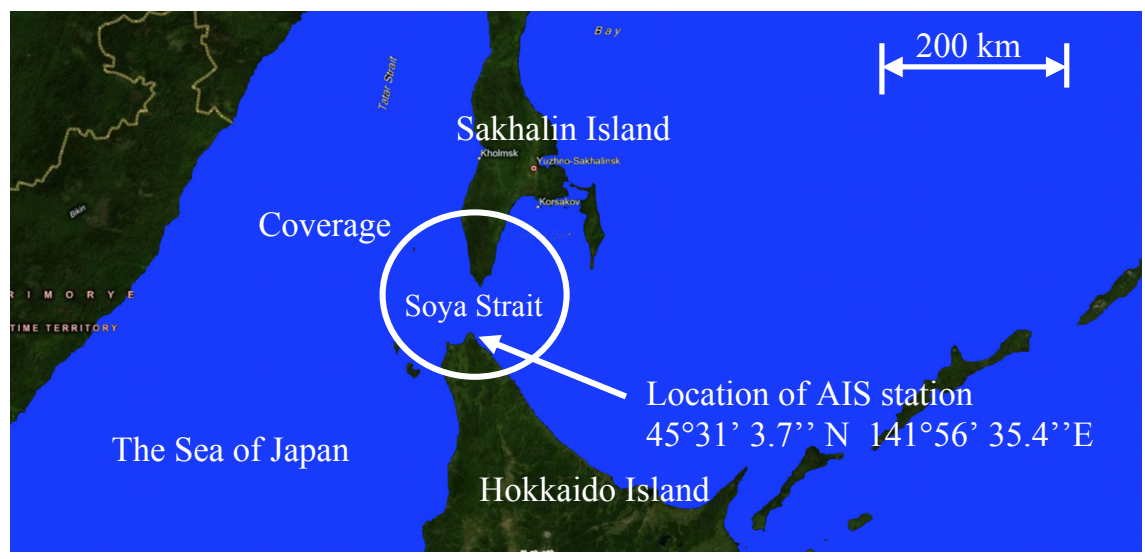

Figure 2: $\quad$ Location and AIS station and its coverage. 

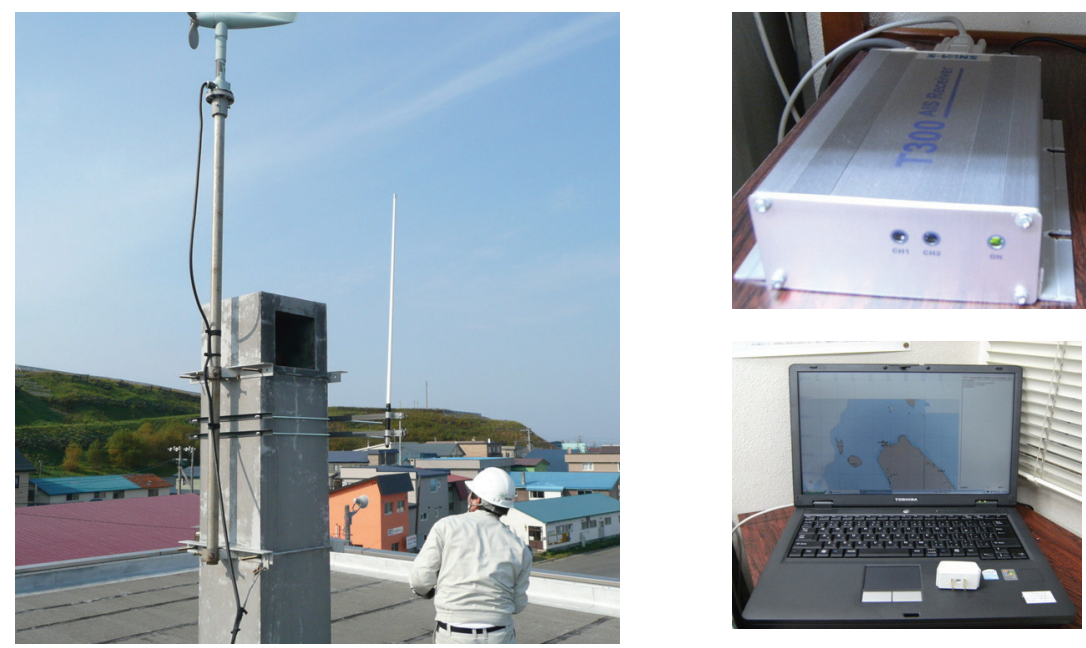

Figure 3: $\quad$ AIS Antenna, T300 receiver and PC monitor.

international voyage, all ocean going vessels over 300 gross tons and all domestic vessels over 500 gross tons are required to be fitted with an AIS.

\subsection{AIVDM messages}

After receiving the AIS radio, dedicated software is required to decode and generate common ASCII characters because the character-string field of AIDVM messages in AIS data are encoded by "6-bit ASCII". Figure 4 shows an example of raw data sent from a T300 AIS receiver to the monitoring PC by way of RS232C serial connection. By decoding these characters (e.g. the underlined characters in Figure 4), information for 1) the name of the ship, 2) the type of ship, 3) call sign, 4) MMSI code, 5) the type of cargo, 6) destination, 7) speed, 8) direction, 9) position of the vessel (GPS/GLONASS acquired longitude and latitude) and other information relating to the ship and her voyage can be extracted. AIS equipped ships send these messages by two waves of VHF radio every 10 seconds (see Figure 5).

09/06/01 00:00:03,!AIVDM,1,1,,A,144OQg002?b;6WnJ>klJ<'9N0@Lt,0*6F

09/06/01 01:20:04,!AIVDM,1,1,,A,144OQg002B:92<6J=c;bS8SN061<,0*15

09/06/01 01:20:04,!AIVDM,1,1,,B,1459rbP00k:9`B $<$ J $>1$ obK ${ }^{\circ}$ aN061<, $0^{*}$ 5D

Figure 4: $\quad$ Example of AIS messages sent by receiver. 


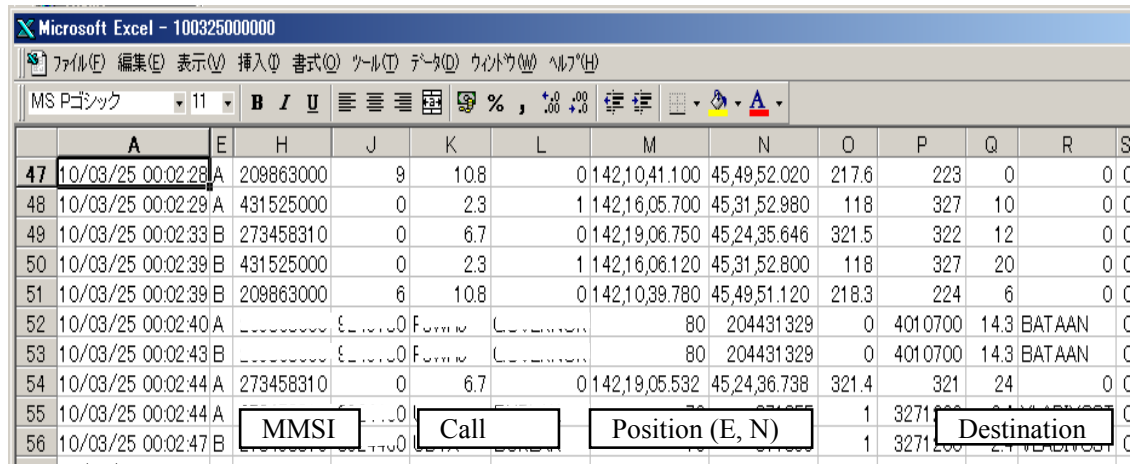

Figure 5: Decoded messages.

\section{Data analysis}

\subsection{Static analysis}

As mentioned above, decoded AIDVM messages contain both time and spatial information of vessel navigations. Static analysis can be done by ship or navigation specific information.

Figure 6 shows the percentage of LNG tankers passing through the Soya Strait from December 2008 to March 2010 by destination countries. AIDVM messages have a part of "destination port" such as "Busan" (one of the biggest Korean Ports) then we can know the destination country of the voyage. Also, Sakhalin projects have their own unique oil or gas shipping ports such as "Pridonogoe" and then tankers can be categorized according to the developing projects.

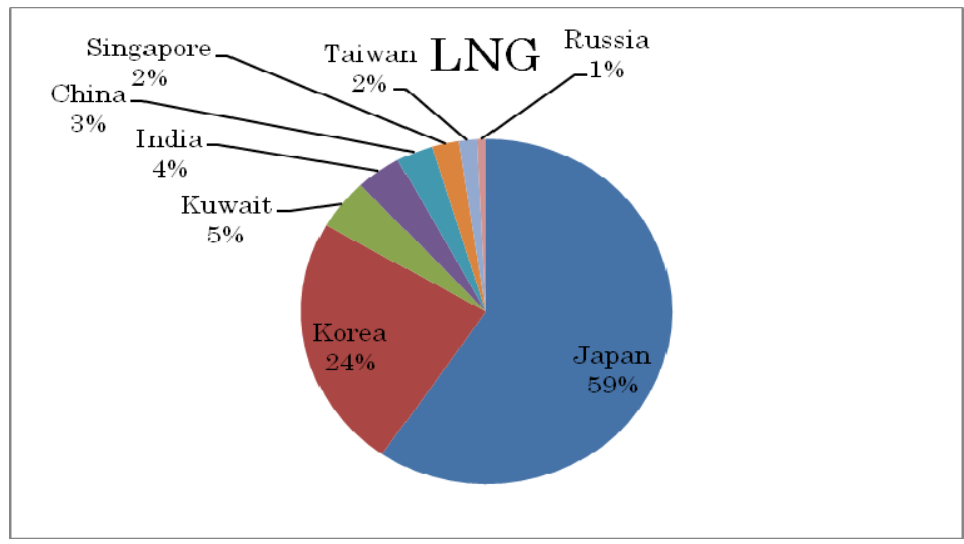

Figure 6: Rate of LNG tankers' destination of Sakhalin 2 passing through the Soya Strait. 
Not only classification, but also quantification analysis can be conducted. In the same period, a total of nine oil tankers were engaged in voyages to transport oil produced by Sakhalin 2 and passed through the Soya Strait 71 times. Meanwhile, 14 LNG tankers were engaged and passed 114 times to convey LNG, (Figure 7 shows respectively). From this analysis, Sakhalin 2 crude oil is transported every 5 to 6 days and LNG in 2 to 3 days. We can get to know that it has already been in "full production period" of this project as of now.
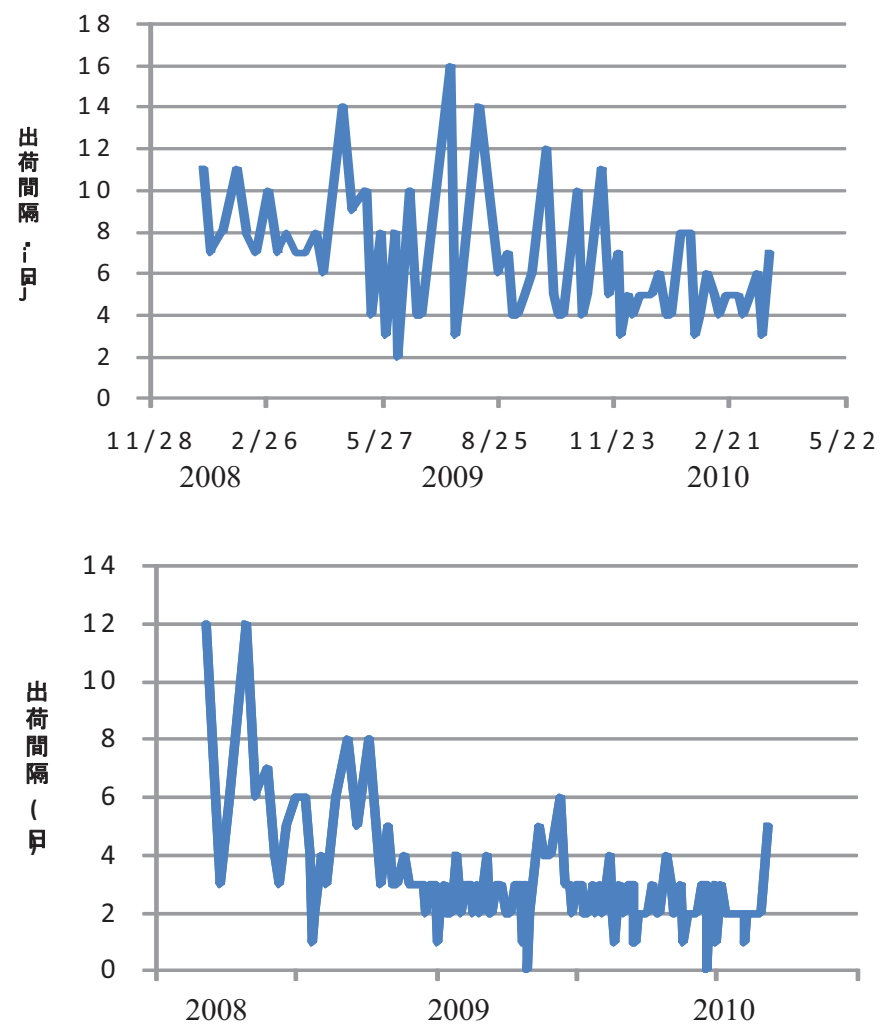

Figure 7: $\quad$ Day interval of oil and LNG tanker shipment for Sakhalin 2.

\subsection{Dynamic analysis}

The dynamic analysis can also be done using both time and spatial information contained in the AIVDM messages. The AIS transponders on board transmit the ship's position obtained by GPS every 10 seconds. Then the migration of each vessel in a certain area can be traced and analyzed.

Figure 8 shows the number of ships (density) passing through each small grid; the darker colour shows the greater number of ships. From this analysis, congested areas of traffic can roughly be specified. 


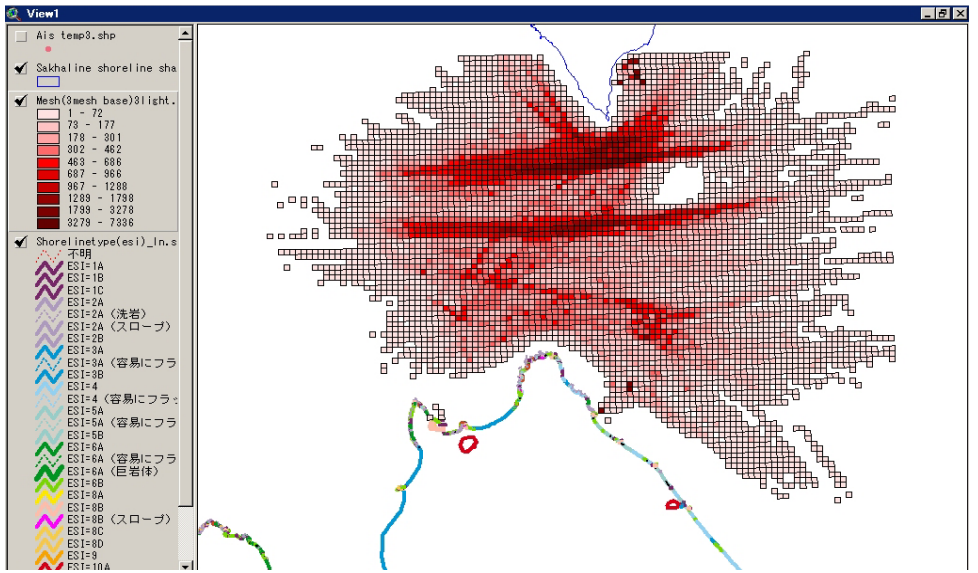

Figure 8: Density of vessels passing through the Soya Strait (Nov. 2008 to Jun. 2009).

Each line of the AIDVM messages shown in Figure 4 presents "a certain ship's position" at "a certain moment". Then a trajectory of a ship can be made by connecting point to point of the vessel by her unique identifier. The Soya Strait is some $40 \mathrm{~km}$ channel between the northernmost of Hokkaidō Island and Dal'nyaya the southernmost of Sakhalin. The channel is divided into eight sections then ships are counted according to their headings of westbound or eastbound (see Figure 9).

Figures 10 and 11 show the result: Soya Strait is one the typical straits of international waters, no additional rules are applied to ships passing through this area at the moment. The traffic flows are not well regulated as the graphs show.

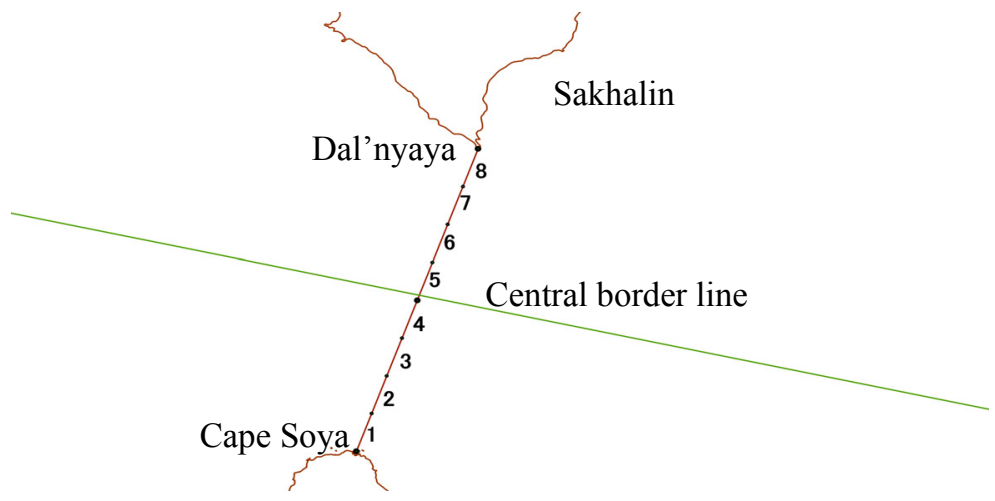

Figure 9: $\quad$ Eight sections of the Soya Strait. 


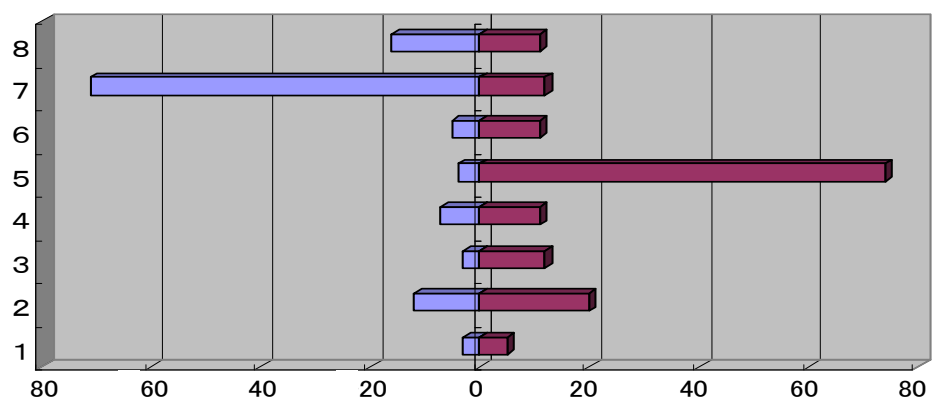

Figure 10: Traffic flow in June 2009 (total 277 ships).

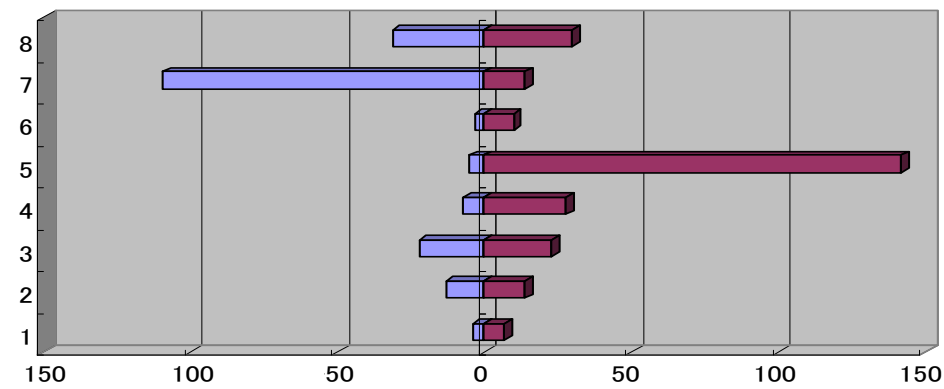

Figure 11: Traffic flow in July 2009 (total 462 ships).

\subsection{Tanker traffic}

As AIDVM messages contain information of the type of ship then the course of tankers can be traced. Figure 12 shows the routes of two tankers, (tankers named ' $S$ ' and ' $Z$ ') carrying Sakhalin 2 crude oil. Two routes are used to avoid the Reef Nijo and these two tankers are likely to choose the west side of the reef to save petroleum. Not only these two tankers but also other traffic of this area tends to be congested at the north-western part of the Reef Nijo.

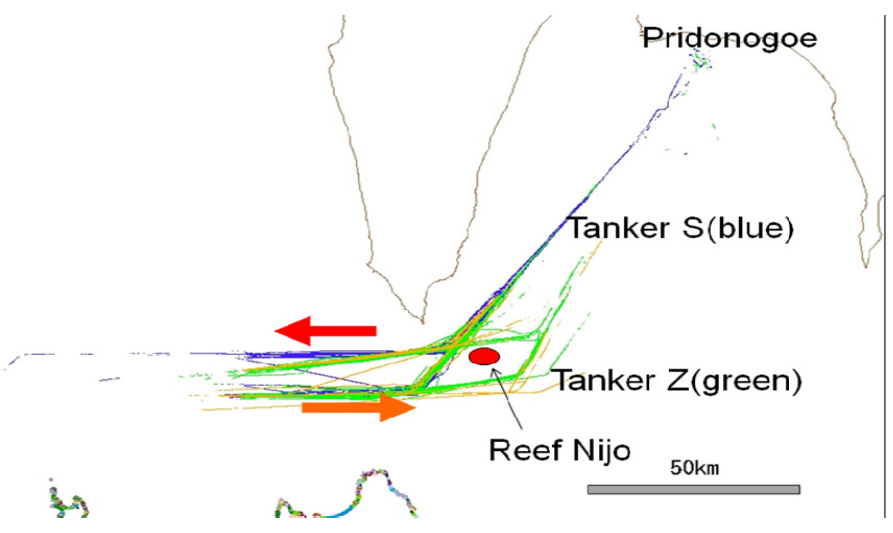

Figure 12: Routes of two tankers engaged in the shipping of Sakhalin 2. 


\subsection{Collision candidates}

It is certain that the traffic congested area has a higher risk of collision or other type of accident. However, the probability of collision is not only depending on the density of traffic because no collision occurs if each ship runs parallel or keeps the same speed with enough distance from each other.

Mathematical models of collisions have been developed since late 1970s by Japanese and Danish engineers and scientists. Fujii et al. [6] developed a model based on the geometrical features of ships in voyage, defined by their size and velocity. This model assumes that a collision happens when two vessels come to a distance defined as the "collision diameter (CD)". Such assumption will induce an understanding that in any encounter between two ships at a distance greater than $\mathrm{CD}$, these ships will be able to avoid a collision.

By this means, a collision risk is depending on the overlap of these circles and the critical distance of collision is called the "minimum distance to collision (MDTC)". Montewka et al. [7] tried to reflect the value of MDTC to ship manoeuvrability.

Before applying the theories of $\mathrm{CD}$ and MDTC to analyze a collision risk using AIDVM messages in the AIS data, it is necessary to develop a model to draw the courses of ships with regard to time and space.

Here, a function to determine the position of vessel (p) from the two parameters of ship's unique identifier $(i d)$ like MMSI and the time $(t)$, this can be written as follows:

$$
\mathrm{f}(i d, t)=\mathbf{p}
$$

This function is not an ideal one but can actually be defined by interpolation using the ship's position at each moment in the AIDVM messages. By this function, every course of the ship underway in a certain area can be calculated (see Figure 13). When the risk of collision is considered, the function (1) has to be applied to two or more vessels with the same value of the parameter $t$. Then, if 100 ships passed through a certain area, the function (1) will be applied at least $100 * 99 / 2$ times (there will be a possibility that three or more ships will collide in a certain area) to generate 100 courses of ships. The number of combinations is enormous then actual application of the function (1) seems to be almost impossible. Then another approach has to be considered.

Here, consider the condition that "a collision never happens" within a small grid again. It is simple because a collision never occurs if two or more vessels are not in a certain grid at the same time. In other words, two or more ships always have to be in a certain grid at the same moment in order to let a collision happen. If a total domain of AIS data is assumed to be a universal set, then an area meeting such condition is always a subset of a universal set and ships in these subsets should be called collision candidates (note: based on Fujii's theory, ships within or close to the CD called collision candidates).

The algorithm aimed to extract such a subset can be implemented only with time parameters once the target grid is determined. Now, the ship named A enters a domain $\Phi$ at the moment of $\mathbf{t} a i$ and goes out at $\mathbf{t} a o$ while ship B enters at $\mathbf{t} b i$ and goes out at $\mathbf{t} b o$, then these two ships never collide under the following 


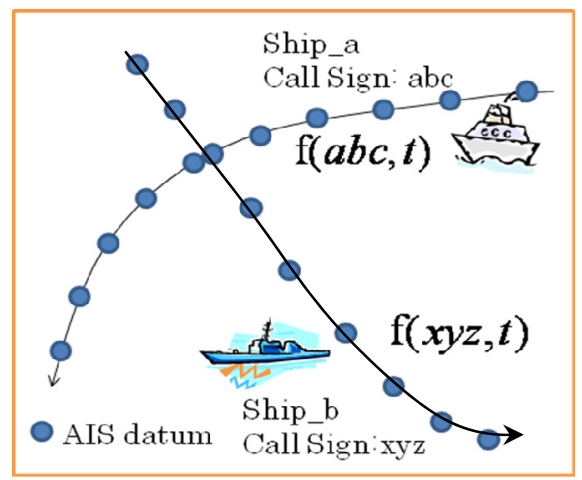

Figure 13: $\quad$ Route of ships generated by function (1).

condition (both $\mathbf{t} a o$ and $\mathbf{t} b i$ are written in serial value). By applying condition (2) to all AIDVM messages, the times of calculation will be greatly decreased. This is simply because critical situations seldom occur.

$$
\mathbf{t} a o>\mathbf{t} b i
$$

\subsection{Result of the analysis}

Considering the size and manoeuvrability of common vessels going through the channel, the area of concern was divided into $1 \mathrm{~km}$ square grids. A unique identifier was allocated to each grid and every ship's position was related with the same identifier of the target grid. The AIS data of this time of analysis was obtained from July 2 to October 8 in 2009, the total number of AIDVM messages to be assessed was 2,254,697. First, all the data of ship positions in each grid were extracted then the condition (2) was applied to choose "the grid of collision candidates". The total number of collision candidates was 9,342 in this

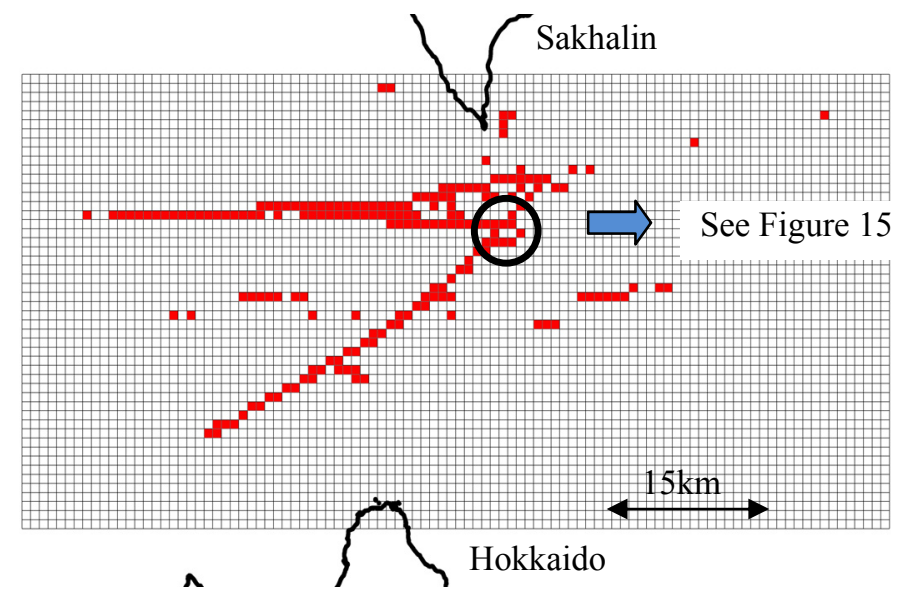

Figure 14: Grids of collision candidates. 
period. The red coloured grids shown in Figure 14 have the vessels of "collision candidates".

Owing to the reduction of positional data to be assessed, detailed situations of ships coming to the close quarter can be analyzed with ease. Figure 15 shows the enlarged area shown by the black circle in Figure 14. Each ship's course is colour-coded in the figure.

Here, the most dangerous crossing seems to have happened in the encircled area of Figure 15. Figure 16 is showing the encircled area of Figure 15 and the lines drawn in Figure 16 show the courses of 4 concerned ships. Ship A and Ship $B$ in this figure were crossed between $03: 44: 30$ to $03: 46: 40$ within 130 seconds on August 31, 2009.

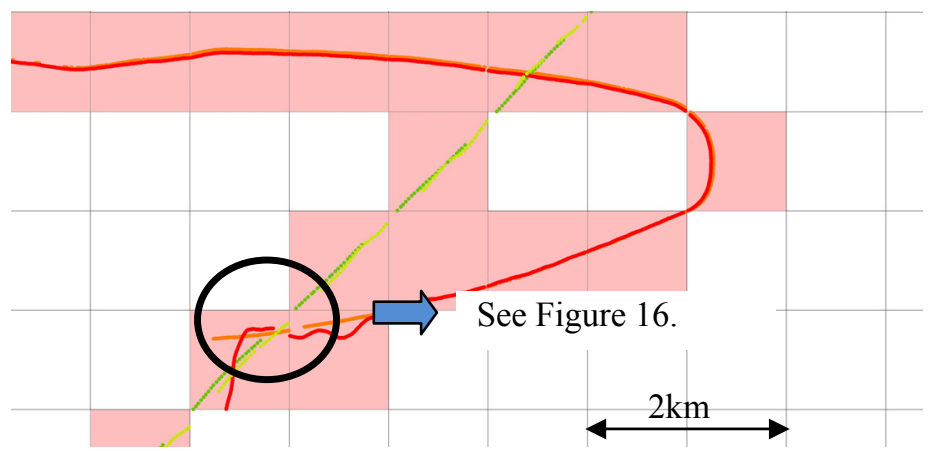

Figure 15: Detailed situation of encircled area in Figure 14.

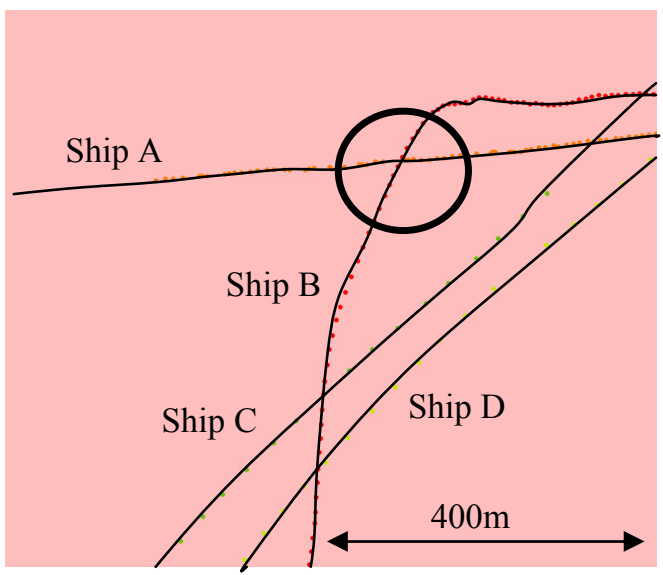

Figure 16: Detailed situation of encircled area of Figure 15.

\section{Conclusions and discussions}

Through this analysis it turned out that both Sakhalin 1 and Sakhalin 2 projects were close to their peak production. Then, with other oil developing projects 
beginning their production, the number of tankers crossing the Soya Strait will necessarily be increasing.

An analytical method proposed by this paper can extract the small areas (grids) containing "near-miss vessels" from a tremendous amount of AIVDM messages effectively. The size of grid will be determined by taking into account of average ship length, speed and her manoeuvring ability. According to Fujii's CD theory, the value of $\mathrm{CD}$ will be larger if the ship size and speed becomes larger, but if ships have a better manoeuvrability then this value will decrease. However, $1 \mathrm{~km}$ of grid length will be almost appropriate considering the speed and scale of the tankers navigating in this area.

There are two streams of tanker routes around the Reef Nijo, as shown in Figure 12. As of the moment, two routes are crossing at the north-western part of the reef because the tankers choose the shortest way to save petroleum. These crossing routes should be segregated to reduce collision risk, as following the regularity of "route separation" which has already been established around the world. Actually, the Gulf of Finland Mandatory Ship Reporting System (GOFREP) is a well known practice of the combination of segregated sea way and information exchange between a ship and VTS (Vessel Traffic Centre). GOFREP has been implemented since 1 July 2004 through co-operation between three countries; Finland, Estonia and Russia [9]. This system was given the award of "Logistics Project of the Year 2008" by the Finnish Logistics Forum for its effects to improve safety in the Gulf of Finland [9]. It is, needless to say, that GOFREP like international-harmonized additional regularity for seaway will be established in the Sea of Okhotsk and the Sea of Japan.

\section{Acknowledgement}

This research was supported by the Ministry of Education, Science, Sports and Culture, Grant-in-Aid (KAKENHI) for research (B), No. 19310110, 2006 -2009.

\section{References}

[1] Murakami, T., Oil and natural gas developing projects in the Sakhalin continent shelf (Chapter one, Japanese), Sakhalin Offshore Oil and Gas Development and Environmental Protection, ed. T. Murakami, Hokkaido University Press: Sapporo, pp. 3-51, 2003.

[2] U.S. Energy Information Administration Independent Statistics and analysis Sakhalin Fact Sheet, data can be obtained from the following URL: http://www.eia.doe.gov/emeu/cabs/Sakhalin/SummaryTable.html

[3] "The hawk and the sea eagle", from the web site of Sakhalin 1 project. This article can be obtained from the following URL: http://www.sakhalin1.com/en/book/book/SakhalinEnglish5.pdf

[4] Newell, J., Sakhalin Oblast (Chapter 11), The Russian Far East A Reference Guide for Conservation and Development, ed. J. Newell, Daniel \& Daniel Publishers; McKinleyville, pp.347-414, 2004. 
[5] Department of Fishery in Prefectural Government of Hokkaido, Situations of Fishery (Part I, Japanese), Hokkaido Fisheries Today, ed. Department of Fishery, Prefectural Government of Hokkaido: Sapporo, pp. 20-61, 2010.

[6] Fujii, Y., Makishima, T., Hara, K., Marine Traffic Technology (Japanese), Kaibundo, Tokyo, 201pp, 1981.

[7] Montewka, J., Hinz, T., Kujala, P., Matusiak, J., Probability Modelling of Vessel Collisions, Reliability Engineering and System Safety, 95, pp. 537589, 2010.

[8] Sonninen, S., Muutinen, M., Rosqvist, T., Development Process of the Gulf of Finland Mandatory Ship Reporting System, VTT Technical Research Centre of Finland, Espoo, 120pp, 2006.

[9] TIEKE (Finnish Information Society Development Centre), the relating article can be obtained from the following URL: http://www.tieke.fi/in_english/news_archive/gofrep_improves_the_flow_of mari/ 